\title{
Precipitation Reactions in Age-Hardenable Alloys During Laser Additive Manufacturing
}

\author{
ERIC A. JÄGLE $\oplus,{ }^{1,4}$ ZHENDONG SHENG, ${ }^{1,2}$ LIANG WU, ${ }^{1}$ LIN LU, ${ }^{1}$ \\ JEROEN RISSE, ${ }^{3}$ ANDREAS WEISHEIT, ${ }^{3}$ and DIERK RAABE ${ }^{1}$
}

1.-Max-Planck-Institut für Eisenforschung GmbH, Max-Planck-Strasse 1, 40237 Düsseldorf, Germany. 2.-Institut für Eisenhüttenkunde, Rheinisch-Westfälische Technische Hochschule Aachen, Intzestrasse 1, 52072 Aachen, Germany. 3.-Fraunhofer Institut für Lasertechnik, Steinbachstrasse 15, 52074 Aachen, Germany. 4.—e-mail: e.jaegle@mpie.de

\begin{abstract}
We describe and study the thermal profiles experienced by various agehardenable alloys during laser additive manufacturing (LAM), employing two different manufacturing techniques: selective laser melting and laser metal deposition. Using scanning electron microscopy and atom probe tomography, we reveal at which stages during the manufacturing process desired and undesired precipitation reactions can occur in age-hardenable alloys. Using examples from a maraging steel, a nickel-base superalloy and a scandiumcontaining aluminium alloy, we demonstrate that precipitation can already occur during the production of the powders used as starting material, during the deposition of material (i.e. during solidification and subsequent cooling), during the intrinsic heat treatment effected by LAM (i.e. in the heat affected zones) and, naturally, during an ageing post-heat treatment. These examples demonstrate the importance of understanding and controlling the thermal profile during the entire additive manufacturing cycle of age-hardenable materials including powder synthesis.
\end{abstract}

\section{INTRODUCTION}

Many classes of alloys owe their high strength to the presence of finely dispersed second phase particles (i.e. phases different from the matrix phase). Since they form by precipitation phase transformations, they are called precipitates, and the materials featuring them, precipitation-strengthened alloys, ${ }^{1}$ Examples are most $\mathrm{Al}$ alloys,${ }^{2-4}$ many Ni-based alloys $^{5-7}$ and some steels. ${ }^{8-11}$ During conventional processing, these materials undergo two subsequent heat treatments. First, in a homogenization treatment in the single-phase region of the phase diagram, i.e. at relatively high temperature, all elements are brought into solid solution. This is followed by a rapid quenching, designed to limit or fully suppress any precipitation during cooling. Precipitates occurring after quenching from the solutionized state are called primary precipitates. Subsequently, the material is annealed at a lower temperature, where the remaining solutes that are now in a supersaturated state are allowed to precipitate. In this age-hardening step, the desired fine dispersion of particles forms. These particles are called secondary precipitates and are typically only up to a few nanometres in size.

During laser additive manufacturing (LAM), the same alloy experiences a very different, unique thermal profile as it is subjected to the subsequent processing steps (see Fig. 1). ${ }^{12}$ First, the alloy needs to be rendered into powder form in an atomization process. For this, the material is melted and the liquid is atomized via gas or water into small droplets that cool down quickly and thus assume a solid powder particle state. ${ }^{13}$ This cooling from the melt is very quick and precipitation is normally suppressed. Therefore, an additional homogenization heat treatment step is usually deemed unnecessary. During LAM, the powder is re-heated to temperatures above the melting temperature. Heating to and cooling from this temperature are also very quick, because of the small size of the heat source (the laser beam), which generates a melt pool that is small in size relative to the underlying substrate or the underlying layers, respectively ("self-quenching effect"). Again, precipitation is 


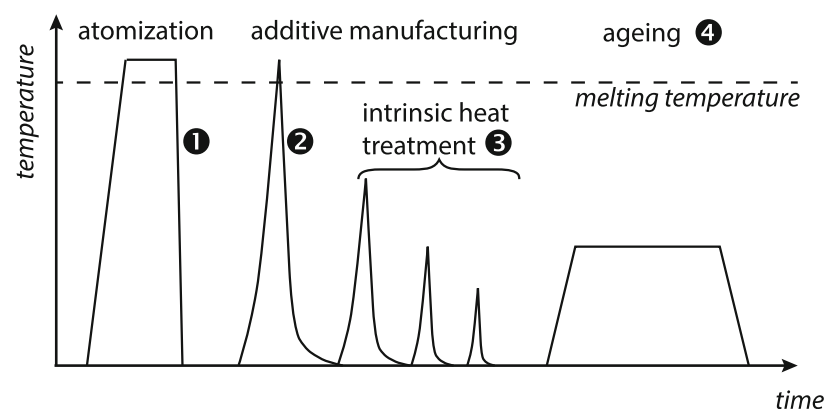

Fig. 1. Schematic image of the complex temperature-time profile experienced by an alloy in the course of the production of an additively manufactured part. The numbers designate specifc processing steps when precipitation, desired and undesired, may occur (see text for details).

typically suppressed during this step. Additionally to the melting and deposition temperature "spike" or "peak", the already-deposited material experiences additional peaks as more material is deposited (in an adjacent track, or an overlying layer, i.e. the adjacent material is in the heat-affected zone (HAZ) of the melt pool). This series of subsequently imposed temperature peaks can be referred to as "intrinsic heat treatment". The maximum temperatures during the peaks are at first quite close to the melting temperature (and indeed some portions of every layer are re-melted during the deposition of the ensuing layer), but the peak temperature drops quickly from layer to layer. Due to insufficient heat conduction to the substrate and/or an installed heating system, the base temperature between the peaks may also be elevated. Finally, an ageing heat treatment analogous to conventional processing may be performed.

During these processing steps, either desired or undesired precipitation may occur during (at least) four of the different processing steps (cf. the numbers in Fig. 1):

(1) During atomization, either if the quenching rate is not high enough to suppress precipitation, or when the time spent in the liquid state is not sufficient to completely dissolve preexisting, coarse precipitates.

(2) During the actual LAM processing, i.e. during cooling from the liquid state after deposition. Again, this might occur if the cooling rate is not fast enough.

(3) During the intrinsic heat treatment, i.e. during temperature peaks.

(4) During the regular ageing heat treatment applied to the final part.

Of the above list, in traditional processing only possibility number 4 would be considered as desired option for precipitation strengthening, as the particles that result from too slow cooling (in steps 1 and 2) are either too coarse, or not dispersed homogeneously throughout the microstructure (e.g., concentrated at grain boundaries), or both. Secondary precipitation during the intrinsic heat treatment is an interesting possibility for desired precipitation that would allow shortening or even completely avoiding subsequent ageing treatment. Primary precipitates forming during solidification may be beneficial for grain refinement.

The control of precipitation during additive manufacturing is important, because solution heat treatment after LAM, which might be used to redissolve unwanted precipitates is not desirable or in some cases even impossible. Solutionizing increases the cost and complexity of the entire manufacturing process and subsequent quenching might induce warpage of the treated part, spoiling the (near-) netshape nature of the LAM process. In some alloys such as the supersaturated Al-Sc-alloy discussed below, solutionizing cannot be used at all to redissolve solutes.

In this paper, examples of all four types of precipitation occurring in LAM-produced alloys are given, after a brief description of the common experimental techniques. The alloys under investigation are a maraging steel, an Al-Sc alloy and a nickel-based superalloy.

\section{EXPERIMENTAL}

\section{Laser Additive Manufacturing}

Two different LAM processes were employed in this work, namely selective laser melting (SLM) and laser metal deposition (LMD). ${ }^{12}$ In SLM, a thin powder layer is spread on a substrate plate using a powder distribution system and selectively melted using a scanning laser beam with a diameter in the range of $100 \mu \mathrm{m}$ to $1000 \mu \mathrm{m}$. After each layer, the build platform is lowered and new powder is applied. Typical layer heights $D_{\mathrm{L}}$ are $20 \mu \mathrm{m}$ to $150 \mu \mathrm{m}$, laser powers $P_{\mathrm{L}}$ are in the range of $50 \mathrm{~W}$ to $1000 \mathrm{~W}$ and scanning speeds, $v_{\mathrm{S}}$, may exceed $2000 \mathrm{~mm} / \mathrm{s}$. In LMD, on the other hand, powder is fed into the melt pool, generated by a laser beam, by a carrier gas being conducted through a co-axial or off-axial nozzle. The entire deposition head consisting of laser optics and powder-feeding nozzle is then moved relative to the fixed substrate plate creating, track by track and layer by layer, a bulk volume. Typical layer heights are $200 \mu \mathrm{m}$ to $1000 \mu \mathrm{m}$, i.e. much larger than in SLM, but travel speeds are two orders of magnitude slower than in SLM (tens of $\mathrm{mm} / \mathrm{s})$. The beam diameter can vary in a wide range $(100 \mu \mathrm{m}$ to several $1000 \mu \mathrm{m})$. Depending on the beam size, the laser power employed in LMD ranges from a few $100 \mathrm{~W}$ to several $\mathrm{kW}$. These different process parameters obviously strongly influence the time-temperature profile experienced by the material. Solidification and cooling rates are generally lower in LMD as compared to SLM $\left(10^{3}-10^{5}\right.$ versus $10^{4}-10^{6} \mathrm{~K} / \mathrm{s}$ ). In Table I, the main process parameters used to produce the materials analyzed in this work are compiled. The volume energy density, $E_{\mathrm{V}}$, introduced by the laser beam is defined as: 
Table I. LAM processes and corresponding main process parameters used for making the materials in this study

\begin{tabular}{|c|c|c|c|c|}
\hline Material & \multirow{2}{*}{$\frac{\text { Scalmalloy }^{\circledR}}{\text { SLM }}$} & \multicolumn{2}{|c|}{ Maraging steel } & \multirow{2}{*}{$\frac{\text { Inconel }^{\circledR} \text { 738LC }}{\text { SLM }}$} \\
\hline Process & & SLM & LMD & \\
\hline Volume energy density, $E_{\mathrm{V}}\left(\mathrm{J} \mathrm{mm}^{-3}\right)$ & 222.2 & 198.4 & 211.6 & 90.0 \\
\hline Scan speed, $v_{\mathrm{S}},\left(\mathrm{mm} \mathrm{s}^{-1}\right)$ & 300 & 150 & 10 & 1000 \\
\hline Layer height, $D_{\mathrm{L}},(\mu \mathrm{m})$ & 30 & 30 & 420 & 20 \\
\hline
\end{tabular}

$$
E_{\mathrm{V}}=\frac{P_{\mathrm{L}}}{y_{\mathrm{H}} v_{\mathrm{S}} D_{\mathrm{L}}}
$$

Here, the hatch distance, $y_{\mathrm{H}}$, defines the distance between adjacent scan vectors (tracks).

\section{Analysis Techniques}

Specimens were deposited using SLM and LMD in the shape of cubes with side lengths of 10$20 \mathrm{~mm}$. They were cut along the build direction (cross-section view) and metallographically prepared. Most of the analyses presented in this work were obtained by using SEMs (scanning electron microscopes; JEOL 6500F and Zeiss Merlin) equipped with EDS (energy dispersive spectroscopy) detectors. For the analysis of fine precipitates, atom-probe tomography (APT) was employed. For this method, samples are lifted from polished crosssections by a FIB (focused ion beam)-liftout technique (using an FEI Helios NanoLab 600i dualbeam microscope) and also sharpened by FIB milling. The samples are measured in a Cameca LEAP 3000 HR X local-electrode atom probe, using laser pulsing at a repetition rate of $250 \mathrm{kHz}$, a pulse energy of $0.4 \mathrm{~nJ}$ and a base temperature of $60 \mathrm{~K}$ (with the exception of the Al-Sc-alloy, for which voltage pulsing at a pulse fraction of $15 \%$ is applied at a base temperature of $40 \mathrm{~K}$ ).

\section{EXAMPLES}

\section{Precipitates in the Raw Powder: A Supersat- urated Al-Sc-Alloy}

Al-Sc alloys have been shown to possess an outstanding combination of strength, ductility and corrosion resistance. ${ }^{14} \mathrm{~A}$ new class of $\mathrm{Al}-\mathrm{Sc}-(\mathrm{Mg}-\mathrm{Zr})-$ alloys called Scalmalloy ${ }^{\circledR}$ has been developed for use in additive manufacturing. ${ }^{3}$ In this alloy, the Sc content is well above the maximum equilibrium solubility of $\sim 0.3 \mathrm{wt} . \%$. Therefore, to obtain a homogeneous supersaturation of $\mathrm{Sc}$ in the $\mathrm{Al}$ matrix, rapid solidification (and further, rapid cooling) needs to be employed. It has been shown that this way, the entire Sc content can be used in the strengthening precipitation reaction yielding $\mathrm{Al}_{3}(\mathrm{Sc}, \mathrm{Zr})$ particles. ${ }^{3}$

We investigated specimens produced by SLM from two different batches of Scalmalloy ${ }^{\circledR}$ powder. The first batch had been atomized by a standard gas atomization technique (ECKA Granules, Fürth, Germany) while the second batch was manufactured using the electrode induction-melting gas atomization (EIGA) technique (TLS Technik, Bitterfeld, Germany). In this crucible-free technique, the bottom part of a rotating bar is melted by induction heating and the resulting flow of liquid metal becomes atomized in a nozzle system using inert gas.

In otherwise identically SLM-produced specimens, the material made with EIGA-atomized powder showed particles of $10-50 \mu \mathrm{m}$ diameter (see Fig. 2b for an example) distributed homogeneously. Analysis by SEM-EDS shows that the precipitates contain approximately 19 at.\% Sc, 7 at.\% $\mathrm{Zr}$ and 74 at.\% Al (with traces of $\mathrm{Si}$ and $\mathrm{Mn}$ ), compatible with the phase $\mathrm{Al}_{3}(\mathrm{Sc}, \mathrm{Zr})$. These particles are already visible in the powder material before processing by LAM (see Fig. 2a). The size of the particles as well as the absence of the particles in the material produced by standard gas atomization suggest that the particles precipitated during the EIGA process, or, more likely, were already present in the material prior to atomization and were not (fully) dissolved during the comparatively short time in the liquid state during this process.

Using the measured volume fraction of particles $(\sim 0.3 \%)$ and their measured composition, the amount of Sc removed from the matrix by being bound inside these large particles can be estimated: 0.09 wt.\%. This small amount of scandium accounts for only a moderate drop in the strength of the material. Fractographic analysis of tensile test specimens made from this material reveal that the large precipitates also do not act as crack initiation sites and hence have only a small deteriorating impact on mechanical strength and ductility.

\section{Precipitation during material deposition: Al-Sc alloy and Ni-base superalloy}

Microsegregation occurs during solidification of most alloys (containing elements with partitioning coefficient not equal to one), provided the cooling rates are not high enough to completely trap solute into the growing crystal. ${ }^{15} \mathrm{We}$ observed microsegregation both in a maraging steel (18Ni-300, see next example) and in a Ni-base superalloy (Inconel $\left.738 \mathrm{LC}^{\circledR}\right)$. Evidently, even the relatively fast cooling 

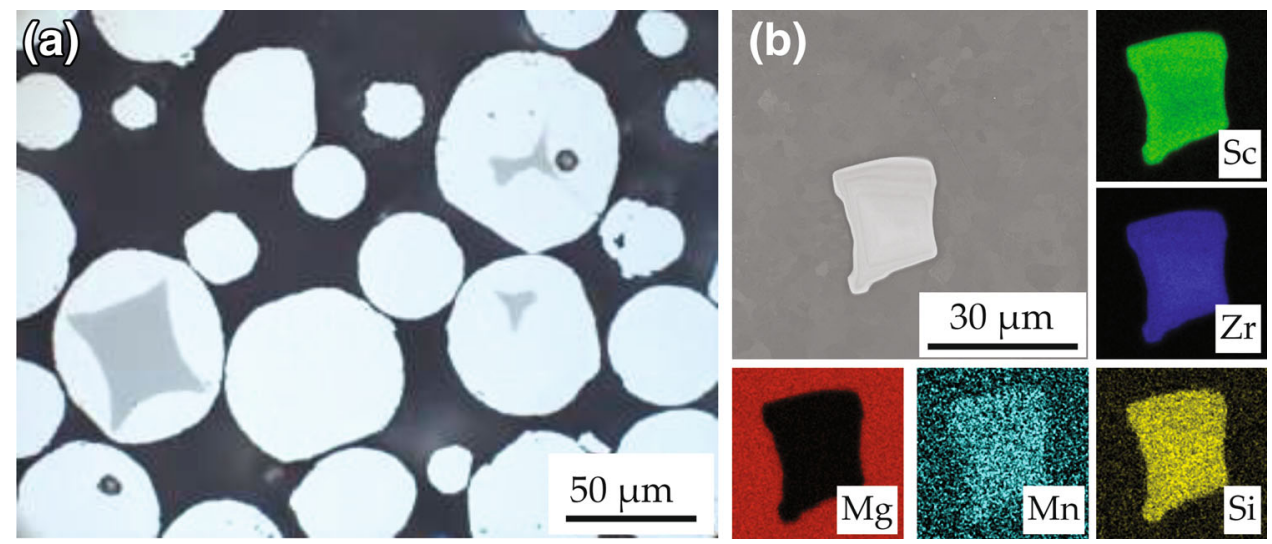

Fig. 2. (a) Light optical micrograph of polished Al-Sc-alloy powder produced by electrode induction-melting gas atomization and used as starting material in LAM. Large precipitates in some of the powder particles are visible. (b) SEM image of an Al-Sc-alloy produced by SLM. A coarse $\mathrm{Al}_{3}(\mathrm{Sc}, \mathrm{Zr})$-precipitate is appearing bright in the backscattered electron detector signal. EDS mappings of various elements are arranged around the SEM image.

rates prevailing in the SLM process (estimated by simulations to be $10^{4}-10^{6} \mathrm{Ks}^{-1}$, depending on process parameters $)^{16}$ are not sufficient for (complete) solute trapping. As the remaining liquid phase becomes strongly enriched in solutes during solidification, the formation of intermetallic phases may become energetically favorable.

In samples of Inconel 738LC ${ }^{\circledR}$ produced by SLM, APT measurements revealed the presence of carbides (TiC), borides (Cr- and Ni-rich) and an intermetallic phase (Zr-, Si-, Ta-, and Mo-rich), mostly in the intercellular and interdendritic regions where the final liquid film solidified (see Fig. 3). Interestingly, the boride phase and the intermetallic phase are always co-located, with the boride often forming an incomplete shell around the intermetallic phase. Note that Scheil-type thermodynamic simulations (using the software ThermoCalc in conjunction with the database TTNI8) do indeed predict both the formation of carbide (TiC) and boride $\left(\mathrm{TiB}_{2}\right)$, but also predict the formation of the coherent $\gamma^{\prime}$-phase (which is the phase that emerges during agehardening, but is not found in our experiments) and other intermetallic phases whose composition does not match the one observed in our experiments.

In samples of Scalmalloy ${ }^{\circledR}$ produced by SLM, various precipitate phases are visible both inside small grains and along their grain boundaries (see Fig. 4). APT measurements allow the determination of the chemical composition of the precipitates, which are compatible with $\mathrm{Al}_{3}(\mathrm{Sc}, \mathrm{Zr})-, \mathrm{Al}_{6} \mathrm{Mn}-$, and Mg-rich precipitates. $\mathrm{Al}_{6} \mathrm{Mn}$ precipitation is known to occur during the ageing of 5083 alloy, which has a similar composition as Scalmalloy ${ }^{\circledR}$ except for the addition of Sc and $\mathrm{Zr}$; however, the concentration observed in the center of the Mg-rich precipitate is significantly higher $(>50$ at.\%) than would be expected for the commonly observed $\mathrm{Al}_{3} \mathrm{Mg}_{2}$-phase ( $\beta$-phase). ${ }^{17,18}$ Instead, the composition is compatible with the $\mathrm{Mg}_{17} \mathrm{Al}_{12}$-phase.
Due to the presence of the precipitates both inside the grains and on the grain boundaries, the exact mechanism of precipitation is not clear. They could emerge in the solid state during cooling after solidification or they could be the result of reheating during the deposition of an adjacent track/ layer (see next example) and afterwards stimulate nucleation during partial re-melting of the layer as the next one is deposited above.

\section{Precipitation During Intrinsic Heat Treat- ment: Maraging Steel}

A characteristic feature of LAM processes, in particular the SLM process, are the high cooling rates experienced by the processed material owing to the small size of the melt pool and effective heat conduction through the substrate and already deposited material. It can therefore be expected that no precipitation in the bulk material during cooling after solidification takes place. This can indeed be shown by analyzing the material using statistical analysis of APT datasets.

We investigated a maraging steel (18Ni-300/ 1.2709/Böhler V720 ${ }^{\circledR}$ ). Maraging steels obtain their high strength and toughness by a microstructure consisting of martensite and finely dispersed intermetallic phases (here: $\mathrm{Ni}_{3} \mathrm{Ti}, \mathrm{Ni}_{3} \mathrm{Mo}$ and $\mathrm{Fe}_{7} \mathrm{Mo}_{6}{ }^{8}$ ) that form during a precipitation hardening heat treatment. ${ }^{9,10,19}$ In Fig. 5a, the radial distribution function (RDF) of pairs of titanium atoms is shown. The curves are obtained from APT datasets measured using conventionally produced material, material produced by $\mathrm{SLM}^{8,20}$ and produced by LMD. In the conventionally synthesized material in the as-produced state, i.e. before precipitation hardening, the RDF assumes a value close to one for all Ti-Ti pair distances. This means that it is equally likely to find a $\mathrm{Ti}$ atom in the close vicinity of another Ti atom as it is finding it further away. Also in as-produced material made by SLM, there is 

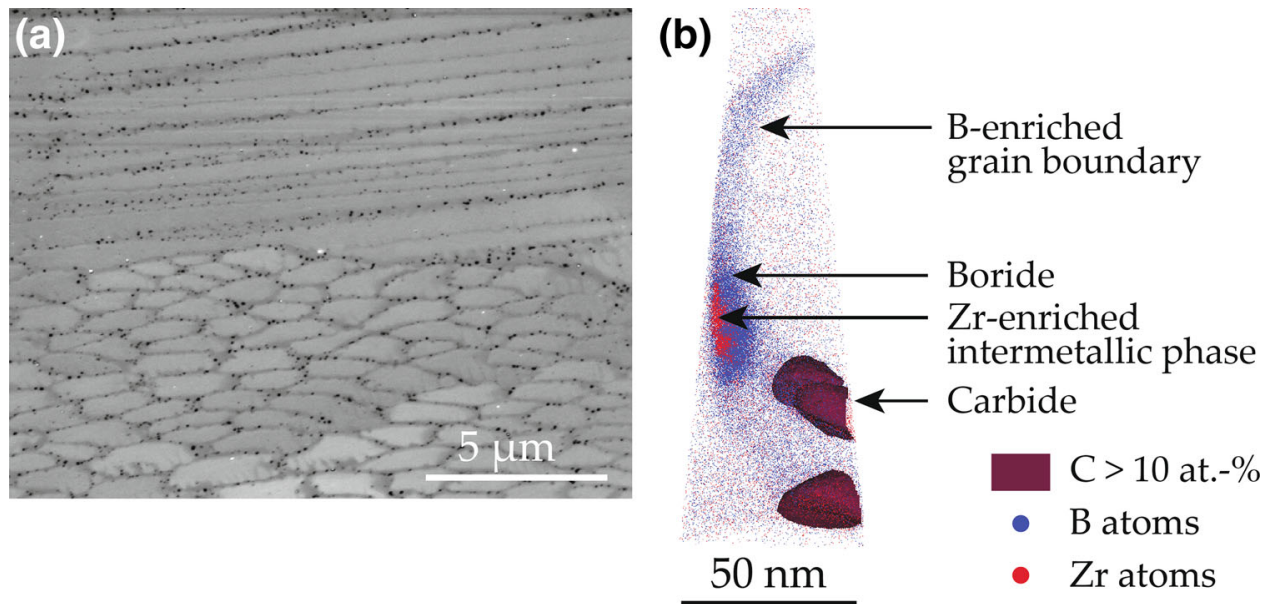

Fig. 3. (a) An image recorded using a focused ion beam showing precipitates (dark) along the intercellular/interdendritic boundaries in the asSLM-produced nickel-base superalloy Inconel 738LC ${ }^{\circledR}$. They form due to microsegregation during the solidification of this alloy. (b) An APT dataset of such a boundary showing boron enrichment on the boundary as well as carbide, boride and intermetallic phase precipitation.
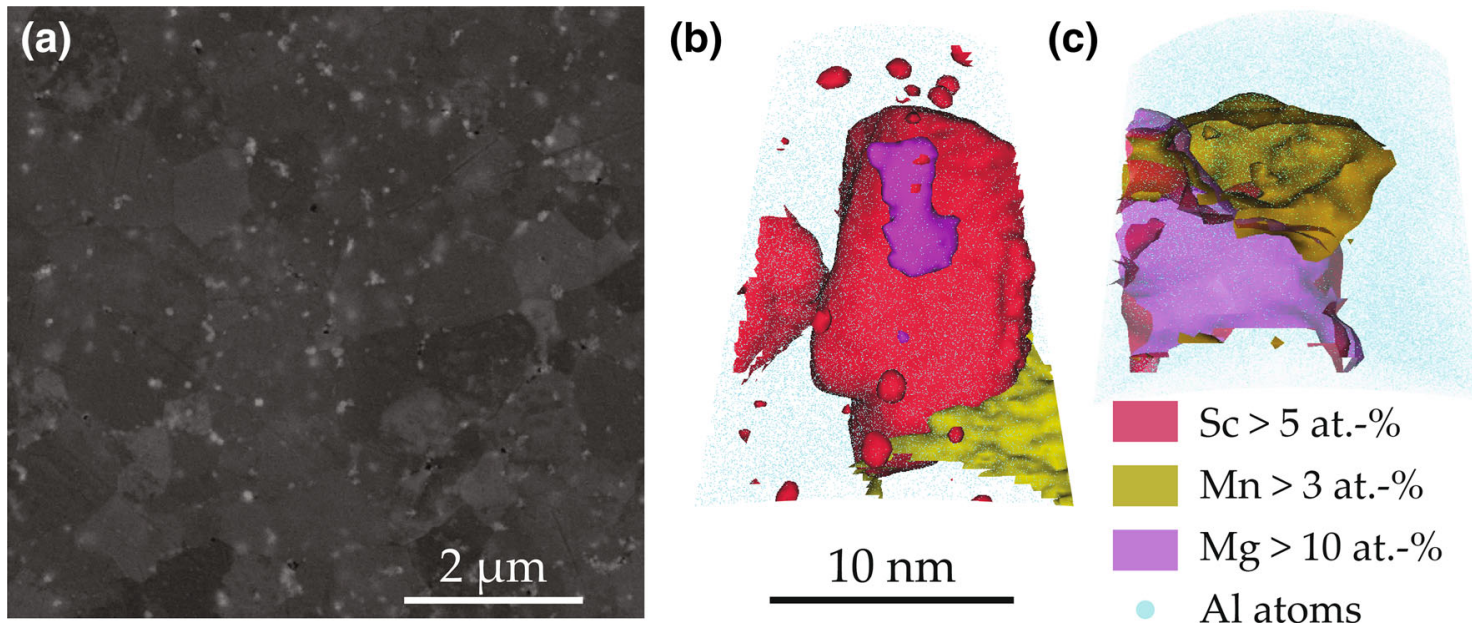

Fig. 4. (a) SEM image showing fine precipitates in a highly supersaturated Al-Sc-alloy that formed most probably during cooling after solidification (SLM). (b) and (c) Two APT datasets showing that in fact three different types of precipitate are formed: $\mathrm{Al}_{3}(\mathrm{Sc}, \mathrm{Zr}), \mathrm{Al}_{6} \mathrm{Mn} \mathrm{and} \mathrm{Mg}_{17} \mathrm{Al}_{12}$.

practically no deviation from unity visible. In LMDproduced material (taken from the middle of the sample), however, there is a clear deviation to values larger than one at small $\mathrm{Ti}-\mathrm{Ti}$ distances. Apparently, in this material, the Ti atoms are likely to already be found in close vicinity to each other without precipitation heat treatment. This is an indication of the onset of precipitation, because the Ti atoms exhibit high mobility (compared to Mo atoms) and therefore form $\mathrm{Ni}_{3} \mathrm{Ti}$ precipitates first.

To prove that this clustering (early stage of precipitation) does not occur during cooling after solidification but rather during the intrinsic heat treatment, i.e. re-heating of the material during the deposition of additional layers, we also investigated samples taken from the very top of the specimen. In the uppermost layer, and in particular in the last track of this layer, no intrinsic heat treatment takes place. Indeed, the RDF corresponding to this situation is again nearly equal to one for all pair distances (cf. the black, dotted line in Fig. 5a).

\section{Precipitation During Ageing Heat Treatment: Maraging Steel}

Finally, further precipitation reactions occur during post-manufacturing heat treatments. Even though some of the initial solute content may not be available for precipitation any more, as explained in the previous examples, the remainder of solute atoms reacts in the same way as in conventionally produced materials. A potential difference exists in the different defect density of LAM- and conventionally produced material. Conventionally produced material is solution heat treated before precipitation and hence in recrystallized state, 
(a)

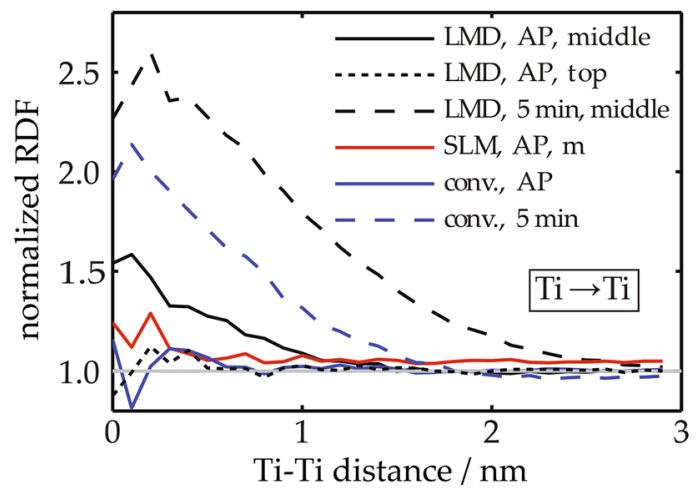

(b)

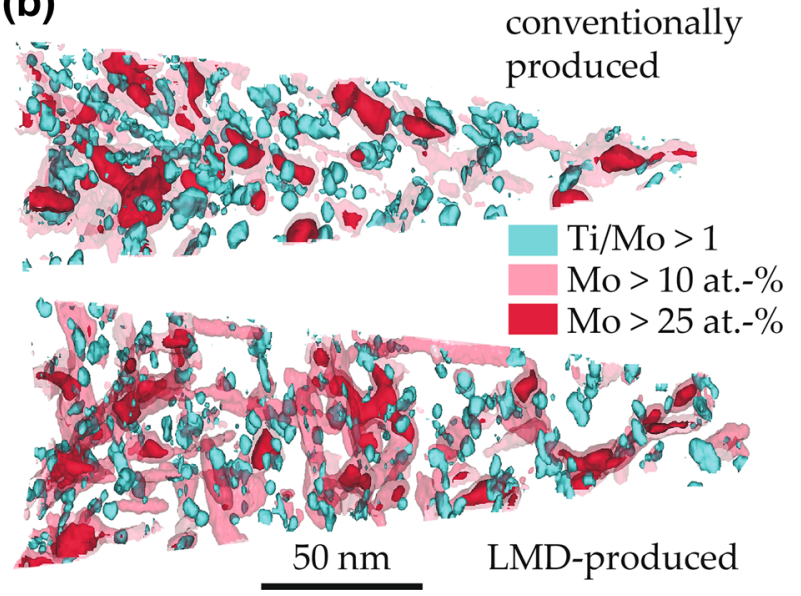

Fig. 5. (a) The radial distribution function of Ti atoms in a maraging steel (18Ni-300) as determined by APT for different processing conditions (conventionally produced, SLM- and LMD-produced) and heat treatments (AP: as-produced, 5 min: ageing at $480^{\circ} \mathrm{C}$, middle and top refer to the respective positions in build direction from where the APT specimens were taken. While the middle layers are exposed to additional heating cycles when depositing further layers, the top layer did not experience such an additional heat exposure). (b) APT datasets comparing the shape, size and number of precipitates present in conventionally produced and LMD-produced maraging steel after post-manufacturing ageing heat treatment $\left(8 \mathrm{~h}\right.$ at $480^{\circ} \mathrm{C}$, i.e. until peak hardness). No significant differences are visible. The three iso-concentration surfaces delineate $\mathrm{Ni}_{3} \mathrm{Ti}^{-}$ precipitates (cyan), $\mathrm{Ni}_{3} \mathrm{Mo}$-precipitates (light red) and $\mathrm{Fe}_{7} \mathrm{Mo}_{6}$-precipitates (dark red), respectively.

which is relatively poor in defects (e.g., dislocations, dislocation cells, and low-angle grain boundaries). Residual stresses generated during the LAM process can be released by plastic deformation, generating a higher density of dislocations. This presence of dislocations could influence the nucleation rate and the spatial distribution of nucleation sites. We observed precipitation in a LMD-produced and postheat treated $\left(8 \mathrm{~h}\right.$ at $480^{\circ} \mathrm{C}$, i.e. until peak hardness is reached) maraging steel and compared the morphology, number density and chemical composition of the emerging particles with the ones observed in a conventionally produced and identically heattreated specimen (see Fig. 5b). Despite the different processing routes, no significant differences between the samples could be observed (note that in other regards, e.g., in the presence of retained and reversed austenite, grain size and morphology, and texture, significant differences between the samples do exist).

\section{CONCLUSION}

We studied desired and undesired precipitation reactions before, during and after laser additive manufacturing in a variety of alloys that gain their strength by precipitation hardening. In particular, precipitates emerging during the following steps were described:

(1) Precipitation of $\mathrm{Al}_{3}(\mathrm{Sc}, \mathrm{Zr})$ during the production of starting material powder in a supersaturated Al-Sc alloy.

(2) Precipitation of carbide, boride and a Zr-rich intermetallic phase during the LAM process, i.e. during solidification in a Ni-based superalloy. Similarly, precipitation of $\mathrm{Al}_{3}(\mathrm{Sc}, \mathrm{Zr})$,
$\mathrm{Al}_{6} \mathrm{Mn}$ and $\mathrm{Mg}_{17} \mathrm{Al}_{12}$ from a supersaturated Al-Sc alloy during cooling after deposition was observed.

(3) Early stages of $\mathrm{Ni}_{3} \mathrm{Ti}$ precipitation (Ti-Ti clustering) during the intrinsic heat treatment occurring in LMD of a maraging steel.

(4) Precipitation of $\mathrm{Ni}_{3} \mathrm{Ti}, \mathrm{Ni}_{3} \mathrm{Mo}$ and $\mathrm{Fe}_{7} \mathrm{Mo}_{6}$ during the ageing heat treatment after LAM in a maraging steel.

These findings reveal that LAM can be used to produce supersaturated alloys that show precipitation during age hardening annealing, as intended. In addition, LAM even provides the potential to dispense with the need of a post-heat treatment by exploiting its intrinsic heat treatment. However, care has to be taken in the production of the powder and in the choice of process parameters to make sure that no undesired precipitation reactions occur in the process chain. Hence, a detailed knowledge of the thermal profile experienced by the material before and during LAM, as obtained, e.g., by process simulations, is necessary.

\section{ACKNOWLEDGEMENTS}

Open access funding provided by Max Planck Society (Max Planck Institute for Iron Research). The authors would like to thank F. Palm, Airbus Group Innovations, for providing the SLM-produced Scalmalloy ${ }^{\circledR}$ specimens, J. van Humbeeck, KU Leuven, for providing the SLM-produced maraging steel specimens and S. Kleber, Böhler Uddeholm $\mathrm{GmbH}$ for providing the conventionally produced maraging steel (Böhler V720). The support by M. Kuzmina, P. Kürnsteiner and S. Ocylok with experiments is gratefully acknowledged. 


\section{OPEN ACCESS}

This article is distributed under the terms of the Creative Commons Attribution 4.0 International License (http://creativecommons.org/licenses/by/4.0/), which permits unrestricted use, distribution, and reproduction in any medium, provided you give appropriate credit to the original author(s) and the source, provide a link to the Creative Commons license, and indicate if changes were made.

\section{REFERENCES}

1. E.J. Mittemeijer, Fundamentals of Materials Science (Heidelberg: Springer, 2011).

2. P.A. Rometsch, H. Zhong, K.M. Nairn, T. Jarvis, and X. Wu, Scr. Mater. 87, 13 (2014).

3. K. Schmidtke, F. Palm, A. Hawkins, and C. Emmelmann, Phys. Procedia 12, 369 (2011).

4. E.O. Olakanmi, R.F. Cochrane, and K.W. Dalgarno, Prog. Mater. Sci. 74, 401 (2015).

5. K. Kunze, T. Etter, J. Grässlin, and V. Shklover, Mater. Sci. Eng. A 620, 213 (2015).
6. L. Rickenbacher, T. Etter, S. Hövel, and K. Wegener, Rapid Prototyp. J. 19, 282 (2013).

7. D. Tytko, P.P. Choi, J. Klöwer, A. Kostka, G. Inden, and D. Raabe, Acta Mater. 60, 1731 (2012).

8. E.A. Jägle, P. Choi, J. Van Humbeeck, and D. Raabe, J. Mater. Res. 29, 2072 (2014).

9. W. Sha, A. Cerezo, and G. Smith, Metall. Trans. A 24, 1221 (1993).

10. R.F. Decker, J.T. Eash, and A.J. Goldman, Trans. ASM 55, 58 (1962).

11. D. Raabe, D. Ponge, O. Dmitrieva, and B. Sander, Scr. Mater. 60, 1141 (2009).

12. D. Gu, W. Meiners, K. Wissenbach, and R. Poprawe, Int. Mater. Rev. 57, 133 (2012).

13. A. Lawley, JOM 33, 13 (1981).

14. J. Røyset and N. Ryum, Int. Mater. Rev. 50, 19 (2005).

15. D.A. Porter and K.E. Easterling, Phase Transformations in Metals and Alloys, 2nd ed. (Berlin: Springer-Science+Business Media, 1992).

16. D. Buchbinder, Selective Laser Melting von Aluminiumgusslegierungen (Aachen: Shaker Verlag, 2013).

17. Y. Zhu, D.A. Cullen, S. Kar, M.L. Free, and L.F. Allard, Metall. Mater. Trans. A Phys. Metall. Mater. Sci. 43, 4933 (2012).

18. R. Goswami, G. Spanos, P.S. Pao, and R.L. Holtz, Mater. Sci. Eng. A 527, 1089 (2010).

19. M.N. Rao, Int. J. Mater. Res. 97, 1594 (2006).

20. K. Kempen, E. Yasa, L. Thijs, J.-P. Kruth, and J. Van Humbeeck, Phys. Procedia 12, 255 (2011). 